\title{
Fathers perceptions and personal experiences of Complementary feeding of children 6 to 23 months in south-western Zimbabwe
}

Authors: Shamiso Alice Moyo ${ }^{1}$, Nikki Schaay²

Affiliations: ${ }^{1}$ University of the Western Cape, Cape Town, South Africa, ${ }^{2}$ University of the Western Cape, Cape Town, South Africa.

Funding: This research received no specific grant from any funding agency, commercial or not-for-profit sectors.

\section{Conflict of Interest: None}

Contributor Statement: SAM- Primary investigator and main author, designed the study, did data collection and analysis along with research write-up. NS- Academic supervisor to the primary investigator provided supervision and support throughout the study.

Contacts: Shamiso Alice Moyo shamyalice@yahoo.com 


\section{Abstract}

Background: The role of fathers in infant and young child feeding has not been explored in Zimbabwe. To date, local research studies on the role of parents in infant and young child feeding have focused more on the mothers than the fathers, and more on breastfeeding than complementary feeding practices, which begin from 6 months of age.

Purpose of study: To explore the knowledge and extent of involvement of fathers in the complementary feeding of children 6 to 23 months in Zimbabwe.

Method: Through a qualitative approach, 10 fathers with children aged 6 to 23 months participated in the study. Local key informants were used to validate information given by fathers. Thematic analysis was used to identify emergent themes.

Results: There has been a notable change in behaviour among the fathers in comparison to what they did 10 years ago. For example, they support their wives with household activities such as playing with the child, fetching water and firewood in bulk and cooking simple meals for their children, though the latter was generally reported as being done only during the mothers' absence. Some of the fathers however, are still mindful of what the predominant culture defines as a father's role in child feeding and thus only do selective activities.

Major conclusion: This qualitative study, a first of its kind, delved into some of the experiences and perceptions of fathers in the complementary feeding of infants 6 to 23 months in Zimbabwe. Rich exploratory insights into the subject matter have been provided and can thus be expanded upon in future research.

Key words: knowledge, involvement, fathers, complementary feeding, children 6-23 months, Zimbabwe. 


\section{Introduction}

Infant and young child feeding (IYCF) practices that are optimal greatly contribute to child health and nutrition (Mukuria et al., 2016). UNICEF, WHO and World Bank Group (2016) go on to specifically mention that IYCF practices are a major determinant of child nutritional status outcomes. A recommended child feeding practice, complementary feeding starts from six months and continues until the child is ready to eat family foods. It is from six months when breast-milk alone is no longer sufficient to meet the nutritional needs of an infant, hence the introduction of other foods becomes necessary (WHO, 2018). In countries with poor resources, the complementary feeding period is often associated with growth faltering (Victora et al., 2010). However, whether infants are being optimally breastfed or not, they could become stunted if they do not receive the required quality and quantity of complementary foods from six months of age (Bhutta et al., 2008).

Despite there being national policy documents in place such as the Zimbabwe National Health Strategy 2016-2020 (MOHCC, 2016), the actual complementary feeding practices of children 6 to 23 months in Zimbabwe are poor according to the National Nutrition Survey of 2018 (Minimum acceptable diet ${ }^{1}$ is $4 \%$, Minimum meal frequency ${ }^{2}$ is $19 \%$, Minimum dietary diversity $^{3}$ is $16 \%$ ). The proportion of children aged 6 to 23 months who receive food from at least four out of the seven recommended food groups is known as minimum dietary diversity and this is one of the core IYCF indicators (WHO, 2008a). The lack of diversity in the diet of young children in rural Zimbabwe is possibly intertwined with the power, choices and decisions (or lack thereof) that various members of the household have and make in relation to infant and child feeding practices.

To date, international and local research studies that have explored the role of parents in IYCF have tended to focus more on the mothers than the fathers, and secondly, have tended to focus more on breastfeeding than complementary feeding (Pryer et al., 2003). The rationale for this female focus has been the fact that mothers spend significantly more time with children, especially during feeding times (McHale et al., 1995). There is currently a dearth of research that has been conducted in Sub Saharan Africa (SSA) on the complementary feeding period, particularly in relation to what role men can play in this period.

Interestingly, a recent study conducted in Ethiopia by Gebremedhin et al. (2017) found that the direct involvement of the husband in IYCF practice increased the dietary diversity of the children aged 6 to 23 months in the household by 13.7\%. This led the authors to conclude that there was an important need to promote and increase the involvement of fathers in IYCF in the study districts. Such conclusions echo earlier recommendations by authors such as Sheriff et al. (2009) who advocated that any intervention designed to increase the rate of breastfeeding should consider a father's role in supporting this feeding practice. Another recent research paper by Sanghvi et al. (2017), compared four case studies of complementary feeding programmes that were implemented in Bangladesh, Malawi, Peru and Zambia. They acknowledged that the improvement of complementary feeding required an understanding of

\footnotetext{
${ }^{1}$ Minimum acceptable diet is a composite indicator of Minimum meal frequency and dietary diversity. It represents minimum standards of IYCF practices

2 This is a proxy for child energy requirements and is the proportion of breastfed and non-breastfed children 623 months of age who receive solid, semi-solid or soft foods or milk feeds the minimum number of times or more.

${ }^{3}$ Dietary diversity looks at both breastfed and non-breastfed infants who are expected to consume at least four of the seven foods groups that are recommended by the WHO
} 
what was driving the feeding behaviours along with how to facilitate the adoption of improved practices in a variety of both cultural and economic settings (PAHO, 2003; WHO, 2008b). From their analysis, one of their recommendations was the targeting of fathers with nutrition messaging for improved complementary feeding behaviour change (Sanghvi et al., 2017).

Furthermore, an earlier study done in Sub-Saharan Africa (Nigeria, Cameroon and DRC Congo) found there to be higher odds of stunting among children of single mothers compared to children whose mothers were in a union (Ntoimo \& Odimegwu, 2014). All these studies validate the importance of the involvement of fathers during the complementary feeding period.

Acharya et al. (2004) notes the adoption of optimal IYCF practices that are specifically related to complementary feeding depends primarily on factors such as decision making and behaviours at family or household level. In most African cultures, the family unit constitutes a central social institution and support mechanism for women and children (Aubel, 2012). The hierarchical relationships between household members and the associated decisionmaking power is an influential component of those cultures White and Klein (2002).

\section{Decision-making roles within the household: the position of men}

Men are often given the title of 'household head', which then inevitably leads to the assumption that they make all the decisions regarding household matters (Matinga, 2002; Njai and Dixey, 2013) In many contexts, men have greater social and economic power along with significant control over their partners, especially in developing countries. One randomized controlled trial from Nepal showed that the exclusion of fathers can lower breastfeeding rates (Mullany et al., 2007). In Kenya, assessments and surveys on IYCF have demonstrated that engaging key influencers, for example fathers, at the household and community level, improves IYCF practices (Dinga, Kiage \& Kyallo, 2018).

Burns et al. (2016) noted in their study in the DRC that when men control the household finances, they also made most of the decisions on how money should be spent, including many decisions regarding health and nutrition practices. The lack of purchasing power of the mothers in this study was identified as one of the key barriers to adequate complementary feeding (Burns et al., 2016).

In a northern Nigerian community, Illiyasu et al. (2010) found that in relation to health, men also decide on the timing and size of family as well as whether their wives will utilise health care services available to them. They may view attending child health-related education and taking the child for immunisations as insignificant activities (Bilal et al., 2016). In a qualitative study, Bilal et al. (2016) noted that it was a real problem for the fathers to go to the health centres. The same was noted by Dougherty et al. (2017), in a study in Niger, where it was noted from discussing with the fathers that they did not perceive it their responsibility to take children to health centres. It was only upon watching community videos related to IYCF and health care that the men began to appreciate their role or importance in this regard (Dougherty et al., 2017).

The gendering of roles and related domains of gender-specific activity are wide-spread phenomena, as was highlighted in studies in Uganda and Bolivia (Aubel, 2005). With men traditionally being seen as mainly responsible for the provision of financial resources (including the provision of food) to support the family's survival. As Aubel (2012) later suggests, due to the nature of their traditional role, men may not possess extensive experience and knowledge on issues of child nutrition. Similarly, Jones et al. (2012) note that culturally 
ingrained attitudes towards women and the gendered division of labour might also be preventing men from supporting women when it comes to reducing their burden of care. It is thus evident that fathers have some form of influence, whether positive or negative during the period of complementary feeding. How they either support or do not support their partners (the mothers) has some bearing on the decisions mothers make regarding some IYCF practices.

\section{Fathers' perceptions towards and involvement in IYCF}

It is important to consider the fathers' perceptions towards IYCF, as a person's perceptions are an integral part of the human decision-making process. Parke (2008) notes that a father's own perception of the role that he believes he ought to play in his child's life might influence his behaviour. For example, if a father believes that it is the mother's job to feed the children, he may not participate in any child feeding during meal times (Vollmer et al., 2015). In a study by Muraya et al. (2017) which looked at gendered decision-making in communitybased child nutrition interventions in rural Kenya, it was observed that during household visits, fathers were generally uninterested in "engaging in the discussions, as they described child nutrition as 'women’s business’ (Muraya et al., 2017:36).

McBride et al. (2005) suggest that the maternal perceptions of a father's role in the family and in child care is also a powerful predictor of how involved the father will be, regardless of a father's own perception of his role. In other words, if the father is not perceived as important by the mother, the mother may adopt certain behaviours or attitudes that discourage the father from increasing his involvement in child care and feeding.

Further, the father's perception of the mothers' opinions, can also affect a fathers' involvement in IYCF (Pasley et al., 2002). Though not looked at in this study, this is food for thought for future studies. Anderson et al. (2010) set out to 'explore how fathers perceive their role in feeding and caring for their infants', and reported that the perceptions of fathers with regard to infant-feeding was influenced by the experience they had with their previous children as well as advice from other fathers.

A number of studies in Sub-Saharan Africa (SSA) [Malawi (Waltensperger, 2001; Matinga, 2002), Congo (Fouts \& Brookshire, 2009) and Ghana (McGadney-Douglas \& Douglass, 2008)], have shown that the knowledge and involvement of men in child nutrition is generally limited. For example, in the latter study it was found that most of the fathers were not involved in the care of their malnourished children, as this was left as a responsibility of female family members. Similarly, in rural Mexico, Perez-Gil-Romo et al. (1993) concluded that men were never involved in infant care and feeding. It is against such a background that Aubel (2011) in her literature review of IYCF interventions recommended that programme planners should take on a more family-focused approach by involving men and other influential household actors. Some recommendations have been put forward on improving male involvement in the infant feeding decision-making process. Specific examples of such recommendations are (1) the 'understanding of household roles and relationships' so as to better understand the role played by men instead of just side-lining them and (2) the 'viewing of men as resources and not as obstacles' so as to actively engage them in strategies that promote optimal IYCF practices (Aubel, 2011).

In Zimbabwe, the prevention of mother-to-child-transmission (MTCT) programme has over the years recognised the importance of involving men in related interventions with the establishment of male mobilisers in the fight against HIV and AIDS as one example of this (MOHCC, 2011). According to a Ministry of Health and Child Care manual "Male Mobilisers Manual”, men usually have little information to make informed decisions about 
health promoting behaviours and this in turn results in their not adopting some of those behaviours being promoted (MOHCC, 2011). Just as men are now recognised as key partners in the prevention of MTCT programmes, men ought to be acknowledged as critical partners in supporting the nutritional health of their infants and/or young children. However, overall, little literature exists on fathers' involvement in child feeding specifically in Zimbabwe, a gap which the present study attempted to begin addressing.

\section{Methodology}

\section{Study Design}

This study was explorative in nature and used a qualitative approach, allowing greater spontaneity in the interaction between researcher and study participants. It allows participants to feel free to respond in greater detail and more openly to the questions asked (Mack et al., 2005). This is an area where little research has been done, and in such cases, according to Malterud (2001), a qualitative approach enables the exploration of meanings of social phenomena as experienced by individuals themselves, in their natural context. The research data were collected through semi-structured, in-depth interviews with fathers. According to Mack et al. (2005:30) "they are an effective method for getting people to talk about their personal feelings, opinions and experiences”. In-depth interviews allow the researcher to gain deeper insight into the fathers' understanding of the importance of age-appropriate complementary feeding (Mack et al., 2005).

\section{Study Population}

The study was done in Tsholotsho district in Matabeleland North Province. Due to the proximity of the district to both Botswana and South Africa, a significant proportion of the young population have migrated to these neighbouring countries in search of work. Families in the district rely heavily on remittances, though some subsistence farming is still practised. The study universe comprised all adult married fathers whose ages ranged between 26 to 42 years with at least one child aged between 6 to 23 months, who were residing in Tsholotsho district at the time of the study.

\section{Sampling and Data Collection}

The sample was purposefully selected. The researcher reviewed the current registers of all children under five years of age that are kept by community volunteers from three different villages of Tsholotsho district. With the assistance of a community volunteer, the researcher purposively selected married fathers associated with ten of the registered children (aged 6 to 23 months) living in the catchment in the area. The selection of the fathers was based on those who had been present in their households in the past three months or more preceding the study.

A total of ten semi-structured, in-depth interviews with married fathers were conducted. Ritchie, et al. (2003) indicate that samples in qualitative research are usually small. They support this notion by stating that if the data are properly analysed, a saturation point will be arrived at where little new evidence will be obtained from additional discussions. Data saturation was reached before the tenth father, and hence there was no need to interview any additional fathers.

The interviews were recorded and field notes taken, allowing the researcher to devote her full attention to listening and asking in-depth questions. This enables a researcher to capture the participants' language (isiNdebele in this case) and tone (Legard et al., 2003). The digital 
recording of each interview was first transcribed by the researcher and then translated into English.

Presser (2005) notes that the researcher's gender and other social statuses could have an influence on the esteem, trust and rapport of an interview and this can either facilitate or thwart access to accurate data. Given that the researcher, a woman, was interviewing fathers, she remained mindful of the gender dynamics that were likely present in conducting the interviews. An example being the researcher wore appropriate clothing that was culturally acceptable to this community, and was respectful even when not agreeing with points made by fathers.

\section{Data quality}

Reflexivity is defined as a process in which the researcher will make known their values, beliefs and biases that may influence the study (Creswell \& Miller, 2000). Before embarking on the data collection process, the researcher documented her initial opinions and beliefs on the father's understanding of the importance of age appropriate complementary feeding in children 6 to 23 months in Zimbabwe. In this regard, the researcher took down notes by the fathers and ensured that the researcher presented the information just as it was said by the fathers. The researcher also recorded her reflections of each interview in her fieldwork journal.

Rigour In this study, rigour was achieved by (i) the initial thorough consideration of reflexivity, (ii) keeping an audit trail and (iii) discuss with each interviewee (during the course of the interview) that the researcher's interpretation of the information that they had shared with her was accurate.

\section{Data Analysis}

Thematic analysis was used to analyse the qualitative data. The researcher read through the transcripts several times so as to be familiar with the data. The researcher then came up with a list of categories and sub-categories along with common sub-themes that related to the study objectives. Such themes and sub-themes are the ones that will appear as major findings of many qualitative studies (Braun \& Clarke, 2006).

\section{Ethics considerations}

Ethical approval to conduct the study was obtained from the Senate Research Committee of the University of the Western Cape in South Africa on the $9^{\text {th }}$ of November 2017 (reference number BMI7/9/8), while local authority to collect data was obtained from the Tsholotsho Rural District Council on the $5^{\text {th }}$ of February 2018.

In order to ensure that all participants voluntarily and in an informed manner consented to participate in the study, they were provided with a participant information letter that explained the objective of the research. It also clearly explained that they have the right not to participate in the research and should not in any way feel threatened by not participating in the study (Mouton, 2001). Each participant was given the opportunity to refuse to participate, although none did. Those who decided to participate in the study were asked to sign the informed consent form. Participants were also given an opportunity to consent to having the interview recorded. In order to reduce bias, the key informant interviews and in-depth 
interviews involved only those participants genuinely willing to take part and share their information in a free manner with the researcher (Shenton, 2004).

The issue of confidentiality was upheld in this research. The researcher explained to the participants that all the information that was recorded from the interviews was for the sole use of this particular research and nothing else and would be kept securely locked away. Furthermore, with regards to anonymity, it was also explained to the respondents that no respondent identification particulars were to be captured on field notes and that pseudonyms would be created which will only be known by the researcher.

\section{Results}

\section{Demographic characteristics of the fathers interviewed}

The fathers that were interviewed ranged in age from 26 to 42 years with an average age of 32 years. They have all been present at their home all or most of the year. Of the 10 fathers interviewed, none were formally employed, they were all doing small, part-time jobs for income such as building, painting or herding of their cattle, while others were subsistence farmers, though selling their surplus. Whilst some of the fathers occasionally sought temporary employment in the neighbouring countries of South Africa and Botswana, others looked for part-time menial jobs in their community. The age of the father's last-born child (which ranged from 7 to 19 months), and their feeding was the focus of this study. There were five boys and five girls.

\section{The perception of the fathers regarding their role in providing food for the family}

The fathers were asked the question on their role regarding complementary feeding. Most of the fathers did not answer directly at first. Instead, they reported providing food, money to buy food and working in the garden, though some said assisting with the feeding and provision of moral support to their wives.

I ensure that my family eats. How? - I do this by providing either food - in- kind or give money to my wife to buy food - Father 5

As a follow-up through probing more specifically on the role played by the fathers in providing food for the family, varying responses came through such as:

I get piece jobs every month and I use some of the money to buy food such as kapenta fish, cooking oil and sugar. I also have a small garden in the yard where my wife and I grow vegetables - Father 10

I buy the food. I have a taxi that is hired out and this brings us income into the home. Providing for the family is how a man can help support his wife - Father 2

I play a financial role-provide money to buy food. I also keep cattle and we get milk. I do farming as well - Father 5

\section{What the fathers cook for their children (personal experiences)}

Most of the fathers mentioned that they were able to cook foods like mealie-meal porridge, boil eggs and 'isitshwala' (stiff porridge), though mostly only in the wife's absence. 
I can cook porridge, sadza (stiff porridge) and relish. I can confidently prepare these. What if my wife travels away-does this mean that the children should starve? As long as she gives me permission to use her pots, am able to cook [he said this with a smile] - Father 9

I can cook porridge with peanut butter. I grew up eating this sort of porridge and learnt how to prepare it from my mother. I make this for my children during my wife's absence-say she woke up early and went to a ladies meeting etc - Father 1

Some of the common recipes that were mentioned by the fathers include enriched porridge and sadza. Porridge is a thin mixture of water and mealie meal which is left to simmer for a few minutes. Thereafter, various ingredients can be added to it whilst still simmering, such as peanut butter (most commonly mentioned), eggs, pounded kapenta, and some salt and sugar to taste. On the other hand, sadza (isitshwala/ stiff porridge) is made from an initial mixture of mealie meal and water and left to simmer for a few minutes. Thereafter, mealie meal is added to it bit by bit, stirring in the pot as it thickens. This is then served with any relish.

\section{Foods fed to the children and knowledge of feeding frequency}

Most of the fathers mentioned that the meals eaten by their children were mainly from the family pot, though some were cooked specifically for the young children. Examples of the foods given from the family pot are: sadza or rice with soup, animal source foods (chicken, beef, goat, kapenta, amacimbi, eggs), green leafy vegetables, lentils. Examples of foods cooked specifically for the children are: mealie-meal porridge enriched with various ingredients such as peanut butter, eggs, crushed dried vegetables.

More specifically, mealie-meal porridge was mentioned as cooked in the morning just for the young children vis-à-vis a lunch meal that is cooked for the whole family including the young children

Most of the fathers knew that their children should eat at least three or more and up to five meals a day. One father said the following:

I believe that he should eat three main meals a day and perhaps, depending on appetite, pick on snacks/fruits in-between his meals - Father 1

\section{The role played by fathers in complementary feeding (personal experiences)}

All the fathers acknowledged that the period of complementary feeding was an important one for the health of their children. Some even went on to explain how they are practically involved with the complementary feeding of their children. With regards to the extent they practically feed the child, most fathers said they fed their babies, though some only did so when the wife was away.

I feed my child when the mother prepares the food for the baby. I have no problem in doing this. I realise that at times as men we tend to worry a lot about what other men think of us instead of worrying more about what is best for our young children. I understand the importance of complementary feeding and feel happy when I see my child eating their food - Father 5

I feed him quite frequently. We have a strong bond and he is happy when I feed him, unlike when his mother feeds him - Father 3 
A lot of times actually. I feed her when my wife is busy, though when she is not well she only wants to be fed by her mother - Father 8

On being asked 'who normally feeds the child', a lot of the fathers admitted that it is mostly done by their wives; with them feeding the children now and then.

My wife, sister, nephews. Me a few times - Father 5

Both of us, though my wife feeds the baby during sickness - Father 9

\section{Discussion}

\section{Reflections of the researcher: initial assumptions and new discoveries}

At the time of conceptualising this study, the researcher's thoughts on the topic were that local fathers were unlikely to have much understanding of complementary feeding. The researcher imagined that this was the case since the local cultural norms in Zimbabwe make childcare for the domain of mothers. It was also the researcher's assumption that, because of this norm, that fathers would also unlikely to have had any practical, hands-on experience with complementary feeding. Interestingly, the researcher's assumptions and pre-conceptions about fathers being disengaged from the practice of complementary feeding was unfounded, at least given the experiences reported by these 10 fathers. The researcher realised that whilst others are still very much influenced by what culture dictates, some fathers may be in some form of transition where at least some of them are now open to directly participating in child feeding.

\section{Support to mothers}

It was interesting to note that most of the fathers indicated that they support the mothers in some form or another so that the mothers get enough time to prepare meals for both the family and the young child. This is perhaps similar to what Bilal et al. (2016) and Thuita et al. (2015) found in their studies when they noted that the fathers selected some childcare activities and responsibilities and reported helping their wives with chores and childcare respectively.

All of the fathers play with their child. Some fetch firewood and water in bulk to support their wives, whilst cooking simple meals mainly in the absence of the wives when they were left alone with the children. The latter type of assistance is similar to the findings from an Ethiopian study by Bilal et al. (2016) where the fathers shared that they would do these activities only if the mother was busy with other household activities or not around. Kansiime et al. (2017), in rural south-western Uganda, found that some men mentioned how working away from home made them less available to participate in child feeding activities. In relation to the current study, there could be some truth in this, as Father 2 clearly indicated the opposite to this as aiding him to participate in child feeding activities: “...but some men like myself have no challenges in helping the wife. After all, I am around and not away in Botswana as before or other time".

Whereas this study did not observe actual IYCF practices or evaluate their outcomes, a study from Kenya by Dinga et al. (2018) noted a positive correlation between paternal support, better infant feeding practices, and nutrition outcomes. Similarly, Jones et al. (2012) showed that the lack of support from spouses was negatively associated with improvements in child diets and feeding practices. 
Bilal et al. (2016) point out that full involvement by the fathers might be difficult, given their socialisation. They identified that in the past, all household chores were considered to be the responsibility of the mother; however, now almost half of the husbands in the community they sampled were now helping the mothers of their children. A newspaper article (Gonye, 2018) in northern Zimbabwe may illustrate how norms are changing. It had an article entitled, 'I don't mind sharing household chores: Epworth man'. It had a picture of the father riding his bicycle with his baby strapped to his back. He said "I even take turns to do household chores with my wife. I cook sadza, while she is seated. People talk a lot in the community, but I don't mind”. This is a similar approach taken by some of the fathers in this study who indicated that they cook for their children. They acknowledged that 'community perceptions' might prevent some fathers from becoming involved in activities they might want to.

\section{Fathers' role in complementary feeding}

Generally, the fathers interviewed here see themselves as playing mainly a 'provider' or 'supplier' role when it comes to complementary feeding, similar to what other researchers such as Bilal et al. (2016) and Thuita et al. (2015) have found in their studies. All of the fathers reported bringing home purchased food and money to buy food. This was achieved by some of the fathers though doing part-time jobs. Similarly, in the rural sub-district of Agincourt, Limpopo province in South Africa (Madhavan \& Townsend, 2007) the authors reported that children whose fathers did not provide financial support to their family were found to be at higher risk of malnutrition. They concluded among many other aspects that paternal financial support was important in facilitating access to nutrition. Dougherty et al. (2017), in five rural villages in the Maradi region of Niger, initially found that men generally took only an indirect and supportive role by providing food and financial resources. Only after seeing videos about infant and young child feeding specifically targeting men, did they report participating in household chores and buying more varied food.

Similar to what the fathers in Tsholotsho indicated, Aubel et al. (2003) found that it is only in crisis situations (such as when emergency health treatment is needed), that men's involvement generally increases.

What struck the researcher was that the fathers who reported cooking talked confidently and positively about it, with smiles on their faces, expressing their willingness to assist in this way. This is contrary to what was found by Thuita (2011) in eastern and western Kenya, where men had no input in any food preparation, as they considered it not to be their work as men.

Parke (2008), cited by Vollmer et al. (2015:3735), wrote: “...because the role of the father is more loosely defined by societal norms than the role of the mother, a fathers' own perceptions of his role in his child's life may drive his behaviour”. This indeed may explain the perceptions of some of the fathers in Tsholotsho, as stated by Father 5:

"I feed my child... I have no problem in doing this...I realise that at times as men we tend to worry a lot about what other men think... I understand the importance of complementary feeding...".

Bearing all this in mind, this study adds new insight into the current literature about the Zimbabwean norms and the extent to which some fathers engage in certain activities at the household level related to complementary feeding. 


\section{Limitations}

The study only focused on a rural area setting, hence the perception and personal experiences of fathers regarding complementary feeding in the urban area was not considered.

Furthermore, the study was conducted in Matabeleland North Province, which is mainly a Ndebele speaking area with Ndebele culture and traditions. As a qualitative study on a small sample of fathers, it was exploratory and conclusions that can be drawn for it are thus quite limited.

This paper also does not examine the responsibilities of government and health care workers to educate parents on complementary feeding. Future research may possibly look into this.

\section{Conclusions}

Many of the findings from this study resonate with what has been found in other African countries (e.g. Bilal et al. 2016, Thuita et al. 2015). As far as we know, this is the first study in Zimbabwe to explore the understanding, experiences and perceptions of the role that fathers can play in the complementary feeding period of children aged 6 to 23 months. The study found that the 10 fathers interviewed did support their wives with household activities such as playing with the child, fetching water and firewood in bulk and cooking simple meals for their children, though the latter was generally reported as being done during the mothers' absence.

Rich exploratory insights into the subject matter have been provided and can thus be expanded upon in future research. Apart from the angle looked at by this study i.e. 'what the fathers perceive as their own role', it is still unclear how mothers perceive the father's role in child feeding practices in the Zimbabwean context.

While generalizations cannot be made from these findings, they may help to set the tone for further research in this domain. Future research might help to determine more certainly the types of fathers in Tsholotsho based on their perceptions towards complementary feeding as this is not conclusive in this study. How culture affects their behaviour and how they perceive certain actions related to complementary feeding should also be explored further in research.

\section{References}

Acharya, K., Sanghv, T., Diene, S., Stapleton, V., Seumo, E., \& Srikantiah, S. et al. (2004). Using Essential Nutrition Action (ENA) to Accelerate coverage with Nutrition Interventions in High Mortality Settings. Arlington, VA, USA: BASICS II Project.

Anderson, K. E., Nicklas, J. C., Spence, M. \& Kavanaugh, K. (2010). Roles, perceptions and control of infant feeding among low-income fathers. Public Health Nutrition 13(4):522-530. https://doi.org/10.1017/S1368980009991972

Aubel, J., Muratova, N., Bosorova, N., Djelilova, L., Allabergenova, D., Shaymanov, N et al. (2003). The role of grandmothers and other household actors in maternal and child health: A qualitative Community study. Navoi, Uzbekistan: Project Hope. 
Aubel, J. (2005). Grandmothers: A Learning Institution. Creative Associates. Washington DC: USAID.

Aubel, J. (2011). The roles and influence of grandmothers and men: Evidence supporting a family-focused approach to optimal infant and young child nutrition. Washington, DC: Manoff Group. http://iycn.wpengine.netdna-cdn.com/files/IYCN-GM-and-Men-Lit-Review060311.pdf

Aubel, J. (2012). The role and influence of grandmothers on child nutrition: culturally designated advisors and caregivers. Maternal and Child Nutrition 8 (1):19-35. https://doi.org/10.1111/j.1740-8709.2011.00333.x

Bhutta, Z. A, Ahmed, T, Black R. E et al. (2008). What works? Interventions for maternal and child undernutrition and survival. Lancet 371:417-440. https://doi.org/10.1016/S0140$\underline{\text { 6736(07)61693-6 }}$

Bilal, S., Spigt, M., Czabanowska, K., Mulugeta, A., Blanco, R., \& Dinant, G. (2016). Father's Perception, Practice, and Challenges in Young Child Care and Feeding in Ethiopia. Food and Nutrition Bulletin 37(3):329-339. https://doi.org/10.1177\%2F0379572116654027

Braun, V. \& Clarke, V. (2006). Using thematic analysis in psychology. Qualitative Research in Psychology 3(2):77-101. Available from:

https://psycnet.apa.org/doi/10.1191/1478088706qp063oa

Burns, J. Emerson, J. Amundson, K. Doocy, S. Caulfield, L. E. \& Klemm, R. D. W. (2016). A Qualitative Analysis of Barriers and facilitators to optimal breastfeeding and complementary feeding practices in South Kivu, Democratic Republic of Congo. Food and Nutrition Bulletin 37(2):119-131. https://doi.org/10.1177/0379572116637947

Creswell, J. W. \& Miller, D. L. (2000). Determining Validity in Qualitative Inquiry. Theory into Practice 39(3):122-130. http://dx.doi.org/10.1207/s15430421tip3903_2

Dougherty, L., Magalona, S., Moreaux, M, Dadi, C. \& Fisseha, T. (2017). The Father Factor: How Community Video Encourages Male Involvement for Better Nutrition and Hygiene Behaviours. Arlington, VA: Strengthening Partnerships, Results and Innovations in Nutrition Globally (SPRING) Project.

Dinga, L. A., Kiage, B. M, \& Kyallo, F. M. (2018). Effect of Father involvement in Infant Feeding on Nutritional Status and Morbidity in Kisumu, Kenya. Journal of Nutrition and Health Science 5(1):1-8. https://doi.org/10.15744/2393-9060.5.105

Fouts, H. N. \& Brookshire, R. A. (2009). Who feeds children? A child's-eye-view of caregiver feeding patterns among the Aka foragers in Congo. Social Science and Medicine 69:285-292. http://dx.doi.org/10.1016/j.socscimed.2009.05.016

Gebremedhin, S. Baye, K. Bekele, T. Tharaney, M. Asrat, Y. \& Abebe, Y. (2017). Predictors of dietary diversity in children ages 6-23 months in largely food-insecure area of South Wollo, Ethiopia. Nutrition 33:163-168. http://dx.doi.org/10.1016/j.nut.2016.06.002

Gonye, V. (2018). I don't mind sharing household chores: Epworth man. Newsday Weekender: 28 July.

Illiyasu, Z. Abubaker, I. S. Galadanci, H. S. \& Aliyu, M. H. (2010). Birth preparedness, complication readiness and fathers' participation in maternity care in a northern Nigerian community. African Journal of Reproductive Health 14(1):21-32. Available from: https://www.ncbi.nlm.nih.gov/pubmed/20695136 
Thuita, F. M. (2011). Engaging Grandmothers and Men in the IYCF Project and Maternal Nutrition. Report of a formative assessment in Eastern and Western Kenya, April 2011. Available from: http://iycn.wpengine.netdna-cdn.com/files/IYCN_Kenya-EngagingGrandmothers-and-Men-Formative-Assessment_0511.pdf

Jones, A. D. Cruz Agudo, Y. Galway, L. Bentley, J. \& Pinstrup-Andersen, P. (2012). Heavy Agricultural workloads and low crop diversity are strong barriers to improving child feeding practices in the Bolivian Andes. Social Science and Medicine 75(9):1673-1684. http://dx.doi.org/10.1016/j.socscimed.2012.06.025

Kansiime, N. Atwine, D. Nuwamanya, S. \& Bagenda, F. (2017). Effect of Male Involvement on the Nutritional Status of Children less than 5 years: A cross sectional study in a Rural South-western District of Uganda. Journal of Nutrition and Metabolism Volume 2017, Article ID 3427087. https://doi.org/10.1155/2017/3427087

Legard, R. Keegan, J. \& Ward, K. (2003). In-depth Interviews. In Ritchie, V. \& Lewis, J., eds. Qualitative Research Practice: A Guide for Social Science Students and Researchers. London: Sage Publications, pp. 138-165.

Madhavan, S. \& Townsend, N. (2007). The social context of children's nutritional status in rural South Africa. Journal of Public Health Suppl 69:107-17.

https://doi.org/10.1080/14034950701355700

Mack, N. Woodsong, C. MacQueen, K. M. Guest, G. \& Namey, E. (2005). Qualitative Research Methods: A Data Collector's Field Guide. North Carolina, USA: Family Health International.

Malterud, K. (2001). Qualitative Research: Standards, Challenges, and Guidelines. The Lancet 358:483-488. https://doi.org/10.1016/S0140-6736(01)05627-6

Matinga, P. U. (2002). Saving Newborn Lives Formative Study. Lilongwe, Malawi: Save the Children US.

McBride, B. A. Brown, G. L. Bost, K. K. Shin, N. Vaughn, B. Korth, B. (2005). Paternal identity, maternal gatekeeping and father involvement. Family Relations 54(1):360-372. https://doi.org/10.1111/j.1741-3729.2005.00323.x

McGadney-Douglass, B. F. \& Douglass, R. (2008). Collective familial decision-making in times of trouble: intergenerational solidarity in Ghana. Journal of Cross-Cultural Gerontology 23:147-160. https://doi.org/10.1007/s10823-008-9064-8

McHale, S. M. Crouter, A. C. McGuire, S. A. \& Updegraff, K. A. (1995). Congruence between mother's and father's family relations and children's well-being. Child Development 66:116-128. Available from: https://www.ncbi.nlm.nih.gov/pubmed/7497819

Ministry of Health and Child Care (MOHCC). (2011). Male Mobilisers Participants Manual, Harare, Zimbabwe.

Ministry of Health and Child Care (MOHCC). (2016). The National Health Strategy for Zimbabwe 2016-2020.

Molyneux, C. S. Murira, G. Masha, J. \& Snow, R. W. (2002). Intra-household relations and treatment decision-making for childhood illness: Kenyan case study, Journal of BioSocial Science 34:109-31. Available from: https://www.popline.org/node/182551 
Mouton, M. (2001). How to succeed in your Master's and Doctoral Studies. Pretoria: Van Schaik.

Mukuria, A. G. Martin, S. L. Egondi, T. Bingham, A. \& Thuita, F. M. (2016). Role of Social Support in improving infant feeding practices in Western Kenya: A Quasi-Experimental Study. Global Health Science and Practice 4(1):55-72. https://doi.org/10.9745/GHSP-D-1500197

Mullany, B. C. Becker, S. \& Hindin, M. J. (2007). The impact of including husbands in antenatal health education services on maternal health practices in urban Nepal: results from a randomized controlled trial. Health Education Research 22(2):166-176.

https://doi.org/10.1093/her/cyl060

Muraya, K. W. Jones, C. Berkley, J. A. \& Molyneux, S. (2017). "If it's issues to do with nutrition...I can decide...": gendered decision-making in joining community-based child nutrition interventions within rural coastal Kenya. Health Policy and Planning 32(5):31-39. https://doi.org/10.1093/heapol/czx032

Njai, M. \& Dixey, R. (2013). A study investigating IYCF practices in Foni Kansala district, Western Region, Gambia. Journal of Clinical and Medicine Research 5(6):71-79.

Ntoimo, L. F. \& Odimegwu, C. O. (2014). Health effects of single motherhood on children in Sub-Saharan Africa: a cross-sectional study. BMC Public Health 14:1145. https://doi.org/10.1186/1471-2458-14-1145

PAHO (2003). Guiding principles for complementary feeding of the breastfed child. http://www.who.int/nutrition/publications/guiding_principles_compfeeding_breastfed.pdf

Parke, R. (2000). Father involvement: A developmental psychological perspective. Conference paper in Marriage and Family Review 29:43-58. Available from: https://www.researchgate.net/publication/297482142_Father_involvement_A_developmental _psychological_perspective

Pasley, K. Futris, T. G. \& Skinner, M. L. (2002). Effects of commitment and psychological centrality on fathering. Journal of Marriage and Family 64(1):130-138. https://doi.org/10.1111/j.1741-3737.2002.00130.x

Perez-Gil-Romo, S. E. Reuda-Arroniz, F. \& Diez Urdanivia-Coria. (1993). Lactania y liudada de los hijos: studio de casos en dos zonas rurales de Mexico. Salud Publica Mexicana, 35:692-699. Available from: http://saludpublica.mx/index.php/spm/article/view/5718/6296

Presser, L. (2005). Negotiating Power and Narrative in Research: Implications for Feminist Methodology. Signs: Journal of women in culture and society 30(4):2067-2090. https://doi.org/10.1086/428424

Pryer, J. A. Rogers, S. \& Rahman, A. (2003). The epidemiology of good nutritional status among children from a population with a high prevalence of malnutrition. Public Health Nutrition 7(2):311-317. https://doi.org/10.1079/PHN2003530

Ritchie, J. Lewis, J. \& Elam, G. (2003). Designing and Selecting Samples, Chapter 4. In Ritchie, J. \& Lewis, J. eds. Qualitative Research Practice: A Guide for Social Science Students and Researchers. London: Sage Publishers. pp. 77-88 and 107-108.

Sanghvi, T. Seidel, R. Baker, J. \& Jimerson, A. (2017). Using behavior change approaches to improve complementary feeding practices. Maternal Child and Nutrition 13(S2):e12406. https://doi.org/10.1111/mcn.12406 
Shenton, A. K. (2004). Strategies for ensuring trustworthiness in qualitative research projects. Education for Information 22(2):63-75. https://doi.org/10.3233/EFI-2004-22201

Sheriff, N. Hall, V. \& Pickin, M. (2009). Father's perspectives on breastfeeding: Ideas for intervention. British Journal of Midwifery 17(4):223-227. https://doi.org/10.12968/bjom.2009.17.4.41670

Thuita, F. M. Martin, S. L. Ndegwa, K. Bingham, A. \& Mukuria, A. G. (2015). Engaging fathers and grandmothers to improve maternal and child dietary practices: Planning a community-based study in Western Kenya. African Journal of Food, Agriculture, Nutrition and Development 15(5):10386-10405.

https://www.ajol.info/index.php/ajfand/article/viewFile/128351/117901

Tolhurst, R. \& Nyonator, F. (2006). Looking within the household: gender roles and responses to malaria in Ghana. Transactions of the Royal Society of Tropical Medicine and Hygiene 100(4):321-6. https://doi.org/10.1016/j.trstmh.2005.05.004

UNICEF, WHO, World Bank Group. (2016). Advancing Early Childhood Development: from Science to Scale. An Executive Summary for the Lancet Series. Available from: https://www.who.int/maternal child adolescent/documents/early-child-development-lancetseries/en/

Victora, C. G. deOnis, M. Hallal, P. C. Blossner, M. \& Shrimpton, R. (2010). Worldwide timing of growth faltering: revisiting implications for interventions. Pediatrics 125(3): e473c480. https://doi.org/10.1542/peds.2009-1519

Vollmer, R. L. Adamsons, K. Foster, J. S. \& Mobley, A. R. (2015). Investigating Relationships between Paternal perception of the role of the father and paternal feeding practices. Journal of Child Family Studies 24:3734-3741.

Waltensperger, K. Z. (2001). Cultural beliefs, Societal attitudes and household practices related to the care of newborns. Lilongwe, Malawi: Save the Children.

White, J. M. \& Klein, D. M. (2002). Family Theories, 2nd Edition. Thousand Oaks, CA: Sage.

World Health Organisation. (2008a). Indicators for assessing IYCF practices: Definitions, Geneva, Switzerland: WHO Press. Available from:

https://www.who.int/maternal child adolescent/documents/9789241596664/en/

WHO. (2008b). Indicators for assessing infant and young child feeding practices, part 1 definitions. Conclusions of a consensus meeting held 6-8 November 2007 in Washington DC. https://apps.who.int/iris/bitstream/handle/10665/43895/9789241596664 eng.pdf?sequence=1

WHO, (2018). Infant and young child feeding. Fact sheet. https://www.who.int/mediacentre/factsheets/fs342/en/ [Accessed 14 October 2018] 